\title{
Application of Current Hemorrhage Control Techniques for Backcountry Care: Part One, Tourniquets and Hemorrhage Control Adjuncts
}

\author{
Brendon Drew, DO, CDR, MC; Brad L. Bennett, PhD, NREMT-P; Lanny Littlejohn, MD, CDR, MC \\ From the Emergency Medicine Department, Naval Medical Center San Diego, San Diego, CA (Dr Drew); the Military and Emergency Medicine \\ Department, Uniformed Services University of the Health Sciences, F. Hébert School of Medicine, Bethesda, MD (Dr Bennett); and the Emergency \\ Medicine Department, Naval Medical Center Portsmouth, Portsmouth, VA (Dr Littlejohn).
}

\begin{abstract}
Decade-long advancements in battlefield medicine have revolutionized the treatment of traumatic hemorrhage and have led to a significant reduction in mortality. Older methods such as limb elevation and pressure points are no longer recommended. Tourniquets have had a profound effect on lives saved without the commonly feared safety issues that have made them controversial. Unique tourniquet designs for inguinal and abdominal regions are now available for areas not amenable to current fielded extremity tourniquets. This article, the first of two parts, reviews the literature for advancements in prehospital hemorrhage control for any provider in the austere setting. It emphasizes the significant evidence-based advances in tourniquet use on the extremities that have occurred in battlefield trauma medicine since 2001 and reviews the newer junctional tourniquet devices. Recommendations are made for equipment and techniques for controlling hemorrhage in the wilderness setting.
\end{abstract}

Key words: hemorrhage, hemostasis, tourniquet, trauma, prehospital, hemostatic agents, topical, dressing, bandage

\section{Introduction}

You are in the backcountry climbing with a friend when suddenly his rope gives way, causing him to fall approximately 10 feet onto jagged rocks. He is awake, alert, and calling to you. As you run in his direction, you note a significant amount of blood soaking through his torn right pant leg. You expose the wound and note an open femur with an amount of bleeding that is obscuring your ability to further assess his wound. What would you do in this scenario? Are you prepared?

Disclaimer: The views expressed in this article are those of the author(s) and do not necessarily reflect the official policy or position of the Department of the Navy, Department of Defense, or the United States Government. B. Drew and L. Littlejohn are military service members. This work was prepared as part of their official duties. Title 17 U.S.C. 105 provides that copyright protection under this title is not available for any work of the United States Government. Title 17 U.S. C. 101 defines a United States Government work as a work prepared by a military service member or employee of the United States Government as part of that person's official duties.

Corresponding author: Brad L. Bennett, PhD, CAPT, US Navy (Ret.), PO Box 235, Bena, VA 23018 (e-mail: brad@wms.org).
Do you know the risks and benefits of different courses of action?

\section{Background}

Uncontrolled hemorrhage from major trauma remains a significant challenge for providers at all levels, both in the hospital and in the field. It is the leading cause of death on the battlefield ${ }^{1,2}$ and the second leading cause of traumatic death in the civilian sector. ${ }^{3}$ Even isolated extremity injury in a fully equipped trauma system can result in preventable deaths. ${ }^{4}$ When evacuation times are prolonged and resources constrained such as in rural, combat, and wilderness medicine scenarios, early hemorrhage control becomes even more critical. Because the primary components of oxygen delivery are cardiac output, hemoglobin, and hemoglobin oxygen saturation, it is understandable that extensive airway and breathing maneuvers are futile if there is no hemoglobin to saturate. Rapid Emergency Medical System (EMS) transport ensures that stabilization and resuscitation can occur expeditiously in civilian emergency departments. However, this paradigm does not hold in most austere 


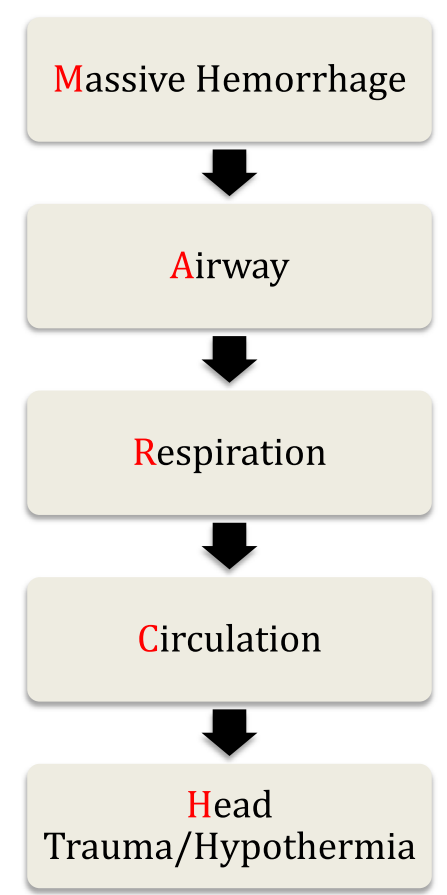

Figure 1. MARCH algorithm for trauma assessment.

settings. The US military utilizes the acronym MARCH (massive hemorrhage, airway, respiration, circulation, head trauma/hypothermia [Figure 1]) to focus efforts on treating rapid exsanguination first in austere settings, even before attempts at managing the airway and breathing/respiration.

If standard crystalloid resuscitation is instituted (normal saline or lactated ringers), the ensuing dilutional coagulopathy can add to the hypothermia and acidosis that form the lethal triad of the deteriorating trauma patient. ${ }^{5}$ Thus, a focus on rapid and effective hemorrhage control before rapid transport is critical in avoiding the need for crystalloid resuscitation or transfusion of blood products in the emergency department. When treating significant hemorrhage, it is better to take the time at the point of injury to control the hemorrhage instead of applying the typical "load and go" mantra taught in most trauma courses. Delayed mortality from sepsis and multiorgan failure syndrome can thus be reduced by immediate and effective early hemorrhage control. ${ }^{6,7}$

For centuries, the methods of hemorrhage control have remained essentially unchanged. ${ }^{8,9}$ Historically, these approaches have all been used with variable success to control bleeding at the point of injury. Research into improved hemorrhage control has been steadily gaining traction over the past century, but it has only been in the last decade that major improvements in prehospital hemorrhage control have been significantly advanced. For example, Tactical Combat Casualty Care (TCCC) guidelines ${ }^{10,11}$ have rapidly evolved as a result of the wars in Afghanistan and Iraq.

The purpose of this paper is to review the current principles of hemorrhage control in the austere setting, to encourage tourniquet use by any level of provider, and to emphasize the significant evidence-based advances that have occurred in the past decade in battlefield trauma medicine.

\section{Hemorrhage First Aid}

Traditional approaches to moderate to severe bleeding have been recommended for many decades (See Table 1). However, recent advances in military medicine to control major bleeding on the battlefield have led to the development of improved tourniquets and hemostatic agents. ${ }^{12-17}$ No review would be complete without covering initial first aid interventions for acute life-threatening hemorrhage. Pressure points over major arteries have long been recommended as a method to stop significant extremity hemorrhage. Although this method can be effective initially, evidence shows that collateral circulation compensates, and bleeding resumes within 60 seconds in the upper extremity and 30 seconds in the lower. ${ }^{18}$ Pressure point use, as well as elevation of the injured extremity, are also no longer recommended by the American Heart Association and American Red Cross, even in situations where definitive care may only be minutes away. ${ }^{19}$ They may be effective as a brief temporizing measure while a tourniquet, hemostatic agent, or pressure dressing is applied, but should not be relied on in isolation or beyond the immediate initial occurrence of hemorrhage.

Table 1. Traditional and current hemorrhage control recommendations

\begin{tabular}{ll}
\hline \multicolumn{1}{c}{ Traditional methods } & \multicolumn{1}{c}{$\begin{array}{c}\text { Current methods } \\
(2010 \text { to present })^{a}\end{array}$} \\
\hline $\begin{array}{l}\text { Direct manual pressure } \\
\text { Pressure points }\end{array}$ & $\begin{array}{l}\text { Direct manual pressure } \\
\text { Pressure points-no longer } \\
\text { recommended }\end{array}$ \\
Elevation of extremity & $\begin{array}{l}\text { Elevation of extremity-no } \\
\text { longer recommended }\end{array}$ \\
$\begin{array}{l}\text { Pressure dressing } \\
\text { Improvised tourniquet (last } \\
\text { resort) }\end{array}$ & $\begin{array}{l}\text { Pressure dressing } \\
\text { Hemostatic agent }\end{array}$ \\
& Commercial tourniquet (eg, \\
& C-A-T, SOF-TT, EMT)
\end{tabular}

C-A-T, Combat Action Tourniquet; SOF-TT, Special Operations Forces Tactical Tourniquet; EMT, Emergency Medical Tourniquet.

${ }^{a}$ From Markenson et al. ${ }^{19}$

${ }^{b}$ Hemostatic agents are discussed in part 2 of this article. 
Direct pressure, well aimed at the site of bleeding is the preferred initial technique. It is very effective, but impractical for the extended period of time a practitioner would experience caring for a patient in the wilderness. Wound packing, the practice of filling the soft tissue defect with enough cloth or dressing material in the hope of compressing the bleeding vessel, may not stop lifethreatening hemorrhage. This traditional approach is generally followed by a pressure dressing, but wound packing can lead to continued unrecognized bleeding, as even medical bandages have a significant wicking effect, drawing blood from the wound without stopping hemorrhage. ${ }^{20}$ The significant advances of managing severe arterial bleeding that have revolutionized battlefield trauma care over the past 10 years are principally due to the research and development of commercial tourniquets and advanced hemostatic agents. ${ }^{10,11}$ These techniques are now bridging into civilian prehospital care and should be strongly considered as items in your wilderness first aid kit for use in austere environments where evacuation to definitive care may be delayed for hours to days. ${ }^{21-25}$

\section{Extremity Tourniquets}

Tourniquets have been used for 2 millennia $^{26}$ yet remain one of the most controversial topics in first aid. ${ }^{23,27-29}$ With equal fervor on both sides, they have been praised for their ability to save lives while being vilified for their complications. $^{24,29}$ Historical concern and cases of tourniquets resulting in unnecessary limb amputations, infections, and other complications have been a result primarily of poor tourniquet selection and technique, ${ }^{30}$ and have resulted in misplaced concern and avoidance of widespread tourniquet use in both civilian and military settings. Until the last decade, there was little actual evidence on tourniquet use to guide care of the injured extremity. ${ }^{31}$ Based on accumulated evidence, every US service member and most NATO personnel deployed to the battlefield are issued a tourniquet and trained on its proper use. The correct use of the tourniquet as recommended by the Committee on Tactical Combat Casualty Care (CoTCCC) can be found in the prehospital trauma life support text ${ }^{21}$ or in the tactical combat casualty care supporting documents (see Tactical Field Care PowerPoint) at: http://www.naemt.org/education/ TCCC/tccc.aspx).

\section{EFFECTIVENESS}

For the patient with significant extremity hemorrhage, the failure to place a tourniquet and stop arterial bleeding can result in death from exsanguination within minutes. The best evidence for tourniquet use in the prehospital environment comes from the experience of a combat support hospital in Iraq. Kragh et $\mathrm{al}^{14}$ prospectively analyzed 428 tourniquets placed on 309 injured limbs, and found that early tourniquet use before the onset of shock was associated with a $90 \%$ survival rate versus $10 \%$ survival if the application was delayed until the casualty was in shock $(P<.001)$. The survival rate was $0 \%$ when a tourniquet was needed but not applied. This original study by Kragh et al ${ }^{14}$ was continued for another 6 months, yielding the largest series to date of 862 tourniquets applied to 651 injured extremities. ${ }^{32}$ Survival was even more striking in this series. Casualties who had tourniquets applied early before shock onset survived $96 \%$ of the time vs $4 \%$ when application was delayed until shock onset. That indicates that the extremity tourniquet should no longer be viewed as a hemorrhage control method of last resort but should be selected first in the setting of major extremity hemorrhage.

Tourniquet use became widespread in the US military in 2005 when they were issued to all deploying personnel. Before 2005, the death rate from peripheral extremity hemorrhage was 23.3 deaths per year, subsequently declining to 3.5 deaths per year after full implementation of the program. ${ }^{33}$ This is an $85 \%$ reduction in preventable deaths due to extremity hemorrhage, further adding weight to the evidence in favor of tourniquet effectiveness. As long as tourniquets are applied appropriately by trained persons, and reevaluated for continued necessity at appropriate intervals, they form a vital part of hemorrhage control.

\section{SAFETY}

Emergency use of tourniquets improves survival and with minimal morbidity. ${ }^{15}$ Reported tourniquet injuries are primarily due to two major factors: metabolic effects are related to ischemia whereas muscle and nerve damage are due to compression. ${ }^{34}$ Wider tourniquets seem to be safer as they allow for the occlusion of blood flow at a lower pressure. ${ }^{35}$ Prior controversy notwithstanding, reviews of recent combat experience have shown them to be life-saving with few, if any, noted complications. Kragh et $\mathrm{al}^{13}$ reported that there was no association of total tourniquet time with morbidity from clots, myonecrosis, rigor, pain, palsies, renal failure, unnecessary amputation, or fasciotomy after application of 428 tourniquets to 309 injured limbs. It is important to note that no amputations resulted solely from tourniquet use, a common assumption historically. The rate of limbs with fasciotomies with tourniquet time of 2 hours or less was $28 \%$ (75 of 272) and beyond 2 hours, it was $36 \%$ (9 of 25), which reached statistical significance $(P=$ .04). However, total tourniquet time was less than the 
"safe" time of 2 hours ${ }^{36}$ in $91 \%$ of the casualties in this study. Four patients $(1.7 \%)$ sustained a transient nerve palsy at the level of the tourniquet. ${ }^{13}$ In a larger series of 499 patients, only $0.4 \%$ of patients required major limb shortening. ${ }^{32}$ Beyond 2 hours of application, slowly releasing a tourniquet should be done in a medical treatment facility with advanced resuscitative capability as prolonged tourniquet time can be associated with clinically significant systemic hyperkalemia and acidosis, leading to, albeit rare, cardiac arrest. In the only reported case from the past 10 years, the patient was quickly converted to sinus rhythm with intravenous fluids and sodium bicarbonate. It was found out subsequently that the tourniquet time had been more than 4 hours. ${ }^{20}$ In summary, tourniquets appropriately applied for less than 2 hours have had little, if any, long-term sequelae for patients.

\section{COMMONLY USED EXTREMITY TOURNIQUETS}

Although there are many tourniquet products made today, only 4 have met criteria for approval by the CoTCCC. These are the Combat Application Tourniquet (C-A-T, 38 mm width; Composite Resources, Rock Hill, $\mathrm{SC}$ ); the Special Operations Forces Tactical Tourniquet (SOF-TT) $27 \mathrm{~mm}$ width, and the SOF-TT Wide, $51 \mathrm{~mm}$ width (Tactical Medical Solutions, Anderson, SC); and the Emergency and Military Tourniquet (EMT), $80 \mathrm{~mm}$ width (Delfi Medical Innovations, Vancouver, BC). The specifications and photos of these tourniquets are found in Table 2 and Figure 2. All 3 of these tourniquets were found to eliminate the popliteal pulse $100 \%$ of the time when applied to the proximal thigh. ${ }^{37}$ In contrast to this finding, another preclinical study comparing the EMT to the C-A-T found that the C-A-T occluded popliteal artery flow in only $12.5 \%$ of subjects whereas the EMT was $100 \%$ successful. ${ }^{38}$ The experience in combat casualties also shows a difference. In casualties received at a combat support hospital, Kragh et $\mathrm{al}^{13}$ found $79 \%$ effectiveness of the C-A-T and $41 \%$ effectiveness of the SOF-TT, whereas the EMT was $94 \%$ effective in controlling hemorrhage. However, when 2 C-A-Ts were used side by side, the effectiveness was raised to $92 \%$, lending credence to the wider-is-better philosophy. ${ }^{13,37}$ Counterfeit C-A-T and SOF-TT tourniquets have been reported to be commercially available and not manufactured to military specification quality standards. In the most recently published comparison of tourniquets, Canadian forces personnel preferred the C-A-T tourniquet. ${ }^{39}$ This study was completed with personnel who had already been extensively trained with the C-A-T and may be a better indicator of the importance of sustainment training rather than superiority of any particular type of tourniquet.

\section{TOURNIQUET APPLICATION}

Kragh et $\mathrm{al}^{40}$ has summarized the use of military lessons learned from the past 10 years regarding tourniquet devices, design, and effectiveness. In several articles looking closely at tourniquet use, the true complications noted were a result of inadequate training and improper selection and tourniquet use. ${ }^{30}$ The experience of the US Army's 75th Ranger Regiment is instructive in this regard. Owing to the rigorous medical training of every member in that unit in tourniquet use, and during nearly a decade of combat experience, their preventable death rate from failure to adequately perform a required prehospital intervention such as tourniquet placement is $0 \%{ }^{41}$ Therefore, it is imperative that any tourniquet selected for use in the prehospital environment be used in the right place, at the right time, and with adequate training in its use before going into the field. The most common mistakes made with tourniquets are summarized in Table 3. It is important to note that the tourniquet width relative to limb girth is an important factor, making the proximal thigh the most challenging place to apply a tourniquet. ${ }^{40,42}$ Indeed, depending on the width of the tourniquet used, more than 1 tourniquet may need to be applied side by side on wounds of an extremity. One of the most common mistakes made in tourniquet application is not tightening the tourniquet

Table 2. Tactical Combat Casualty Care recognized commercial tourniquets

\begin{tabular}{|c|c|c|c|c|c|}
\hline Tourniquet & Mechanism & Width & One-handed & Weight & $\operatorname{Cost}{ }^{a}$ \\
\hline EMT & Bladder device & $80 \mathrm{~mm}$ & No & $7.8 \mathrm{oz}$ & $\$ 300$ \\
\hline C-A-T & Windlass & $38 \mathrm{~mm}$ & Yes & $5.6 \mathrm{oz}$ & $\$ 30$ \\
\hline SOF-TT & Windlass & $27 \mathrm{~mm}$ & Yes & $4.7 \mathrm{oz}$ & $\$ 27$ \\
\hline SOF-TT Wide ${ }^{b}$ & Windlass & $51 \mathrm{~mm}$ & Yes & $3.4 \mathrm{oz}$ & $\$ 30$ \\
\hline
\end{tabular}

\footnotetext{
EMT, Emergency Medical Tourniquet; C-A-T, Combat Action Tourniquet.

${ }^{a}$ Approximate.

${ }^{b}$ The Special Operation Forces Tactical Tourniquet (SOF-TT) Wide is a second-generation version with a wider strap and metal buckle closure that does not require secondary screw tightening to secure properly.
} 
A

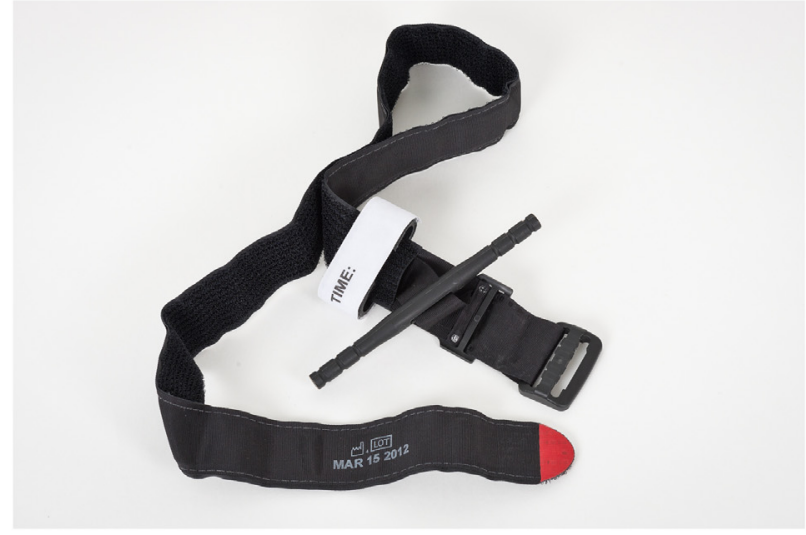

C

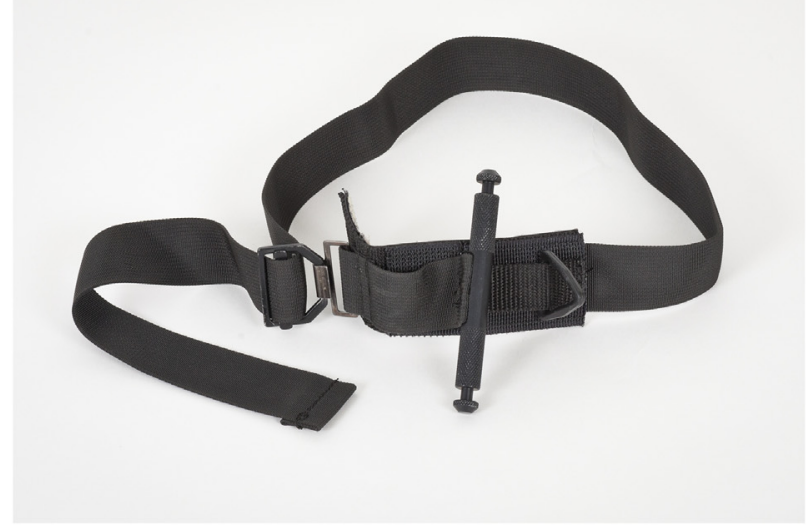

B

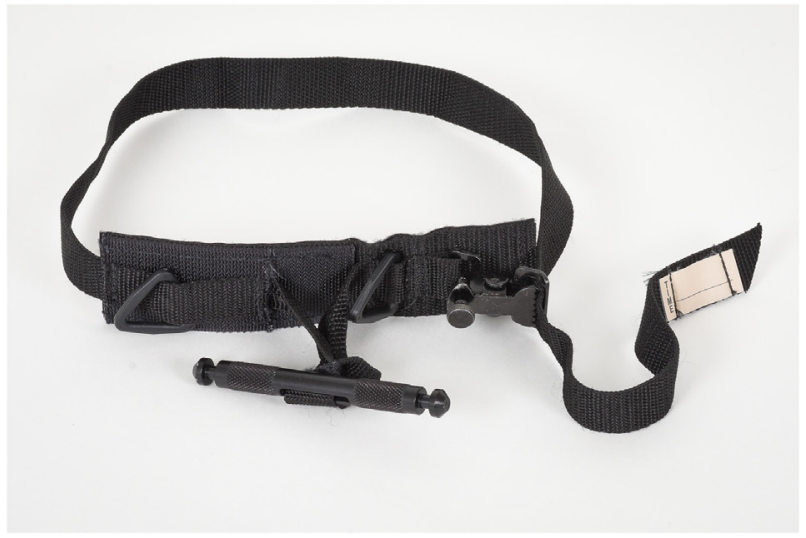

D

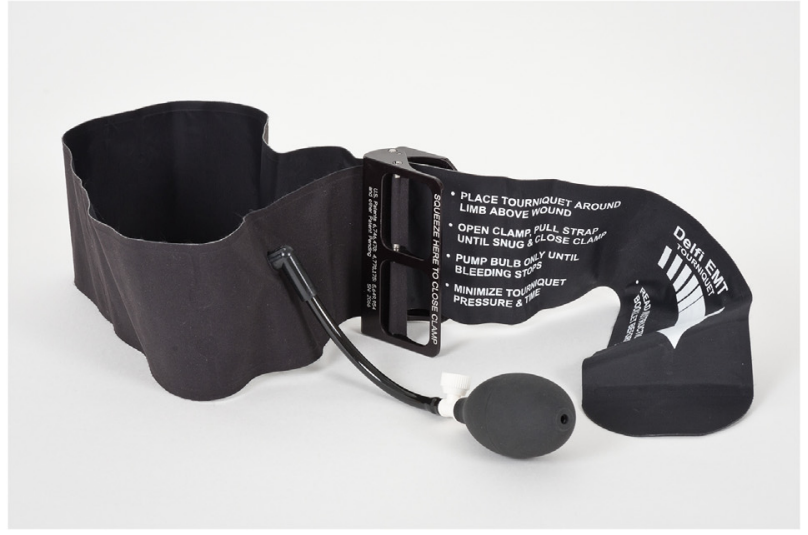

Figure 2. (A) Combat Action Tourniquet. (B) Special Operations Forces Tactical Tourniquet. (C) Special Operations Forces Tactical TourniquetWide. (D) Emergency and Military Tourniquet.

enough to occlude arterial flow. That is termed a venous tourniquet and allows for arterial inflow while venous outflow is impeded. In this setting, the persistence of venous tourniquets can engorge the distal limb, drain core blood, lead to paradoxical bleeding, and worsen shock. ${ }^{15}$ Closed wounds may develop a compartment syndrome, which can require fasciotomy. In one review of 79 prehospital combat applications of tourniquets, $83 \%$ of limbs had palpable pulses present, and providers were often surprised at how tight the tourniquet must be to occlude arterial flow. ${ }^{43}$

\section{USE OF TOURNIQUETS}

Practical experience with training and application of the 3 TCCC recommended tourniquets reveals several key points. First, tourniquets should be easily accessed in a first aid kit so that they are ready to be used. However, they should not be worn on the outside of the body or backpack. In a study assessing 166 tourniquets exposed to the environment for 6 months in Afghanistan, 14 of 166 broke on application, and efficacy was $63 \%$ vs $91 \%$ when compared with unexposed tourniquets $(P<.001) .{ }^{44}$ A second study with a comparable design found similar results, but there was no difference in tourniquets removed from the manufacturer's wrapping vs those that were not when both were stored in first aid kits. ${ }^{45}$

Second, the tourniquet must be properly placed in the right location on the injured extremity. A tourniquet should be placed 2 to 3 inches proximal to the wound. There is no evidence that placement on a long bone such as the femur is more effective than placing the tourniquet on the forearm or leg if the wound happens to be on a 2-bone location. Swan et $\mathrm{al}^{18}$ found that tourniquets were effective at eliminating distal pulses in both the forearm and leg when applied to healthy volunteers. On the distal thigh, Hunter's canal is a location near the medial condyle of the femur that protects the superficial femoral artery from compression. Tourniquets placed here were found to be effective only $67 \%$ of the time. ${ }^{13}$

Third, it is imperative to pull the initial strap through the tourniquet buckle as tight as possible on the limb 
Table 3. Common tourniquet mistakes based on battlefield lessons learned ${ }^{\mathrm{a}}$

\begin{tabular}{|c|c|}
\hline Tourniquet mistakes & Comments \\
\hline Not using TQ when it should be & $\begin{array}{l}\text { Combat data show survival as low as } 0 \% \text { if TQs are not used when they } \\
\text { should be. }\end{array}$ \\
\hline $\begin{array}{l}\text { Using TQ for minimal bleeding when control with } \\
\text { other methods would suffice }\end{array}$ & $\begin{array}{l}\text { Owing to potential morbidity with prolonged use, take care to use only as } \\
\text { needed for arterial bleeding }\end{array}$ \\
\hline Putting TQ too proximal & $\begin{array}{l}\text { To minimize potential tissue damage, TQ should be placed 2-3 inches } \\
\text { above wound. }\end{array}$ \\
\hline $\begin{array}{l}\text { Removing TQ when casualty is in shock and } \\
\text { bleeding not controlled }\end{array}$ & $\begin{array}{l}\text { Survival is as low as } 4 \% \text { if TQ is placed after shock onset, even lower if } \\
\text { removed when in shock. }\end{array}$ \\
\hline Removing TQ when there is short transport time & There is very little morbidity with necessary TQ use for less than 2 hours. \\
\hline Not making TQ tight enough & $\begin{array}{l}\text { Tighten TQ until the distal pulse is absent; venous tourniquets may result } \\
\text { in compartment syndrome. }\end{array}$ \\
\hline Not using second TQ when needed & $\begin{array}{l}\text { Large limbs require increased TQ width; this can be done by adding } \\
\text { second TQ side by side. }\end{array}$ \\
\hline Waiting too long to put TQ on & $\begin{array}{l}\text { Heavy bleeding needs to be stopped immediately; evaluate for TQ } \\
\text { conversion as soon as possible. }\end{array}$ \\
\hline Periodically loosening TQ & $\begin{array}{l}\text { Loosening TQ will hasten further bleeding without providing effective } \\
\text { perfusion of injured extremity }\end{array}$ \\
\hline
\end{tabular}

TQ, tourniquet.

${ }^{a}$ Use evidenced-based tourniquets approved by the Committee on Tactical Combat Casualty Care. See Butler et al. ${ }^{21}$

before turning the windlass or inflating the cuff. When this is done adequately, 3 turns of the windlass will make the C-A-T tourniquet effective in $90 \%$ of cases. $^{45}$ Clumpner et $\mathrm{al}^{46}$ recently concluded that the C-A-T band routing through the buckle, which can be done either singly or doubly, affects time to hemorrhage control and the overall volume of blood lost. Single routing proved to give a faster application time, thereby preventing greater blood loss. ${ }^{46}$ On the leg, however, practical experience indicates that the C-A-T should have the strap routed through both ends of the buckle to prevent excessive pressure from loosening the strap during final tightening of the windlass.

\section{TOURNIQUET CONVERSION}

Conversion is the term used to describe the active (and ongoing) reevaluation of the need for continued tourniquet use. This process includes any procedures along the continuum of replacing the tourniquet with a hemostatic agent or pressure dressing, or even the complete removal of the tourniquet. Conversion is a necessary skill for experienced military providers to master, as many tourniquets are placed during mass casualty scenarios or the care-under-fire stage of TCCC. The safety profile, ease and speed of application, and potential life-saving effects of properly applied tourniquets during these situations result in the application of tourniquets that sometimes are not needed once the casualty is evaluated in a more controlled situation. ${ }^{47}$ Furthermore, a state of lower blood flow in the injury area may have allowed adequate clotting to ensue with improved control of bleeding. When the casualty is moved outside the imminent danger area, the need for further tourniquet use should be reevaluated immediately. The first step is to apply, but not tighten, a second tourniquet proximal to the first. This first step is imperative if the casualty starts to bleed and the original tourniquet fails during an attempt to retighten, and if the casualty starts to bleed more as blood pressure increases during resuscitation. The second step is to clear the wound of dressing material and debris to allow a clear view of potential bleeding during loosening. The final step is to slowly loosen the tourniquet to evaluate the need to continue tourniquet use, with application of an appropriate dressing if the tourniquet does not need to be continued.

It is important to remember that loosening a tourniquet to allow blood flow into the injured limb simply results in intermittent exsanguination and is not correct conversion. Tourniquet conversion is an especially important skill to master in the backcountry, where evacuation times may be several hours to days. Because the safe "warm ischemia" time for tourniquet use is 2 hours or less, conversion would be most effective if attempted before this point. ${ }^{13}$ Tourniquets left on more than 6 hours have the potential to cause significant nerve and soft tissue damage, which may lead to life-threatening reperfusion injury. If a tourniquet has been on for more than 6 hours, then conversion outside of a facility with intensive care unit level of care is not recommended. 


\section{Junctional Tourniquets}

Owing to the overwhelming success of tourniquets in controlling extremity hemorrhage, the US military has seen a change in focus of prehospital hemorrhage control research. A review of casualties from the past 10 years found that $90.9 \%$ of deaths were due to hemorrhage. Sites of lethal hemorrhage were truncal (67.3\%), junctional $(19.2 \%)$, and peripheral-extremity $(13.5 \%){ }^{33}$ Junctional regions are those areas of the body where the extremities join the torso, such as the groin or axilla, and are too proximal for extremity tourniquet application. If one of the new junctional tourniquet devices were applied to these casualties (19.2\%), it is estimated that 3 deaths per month would have been saved over the last 10 years of combat operations. ${ }^{48}$ There is now a small body of evidence that control of hemorrhage from injuries too proximal to be controlled with an extremity tourniquet and in areas too difficult to compress to render hemostatic dressings effective can be obtained with these mechanical compression devices applied to proximal arterial structures. Advanced wilderness medicine practitioners should be aware of these new devices to control junctional hemorrhage.

Three junctional devices are currently cleared by the Food and Drug Administration. The devices are the SAM junctional tourniquet (SJT; SAM Medical Products, Portland, OR), Combat Ready Clamp (CRoC; Combat Medical Systems, Fayetteville, NC), and Junctional Emergency Treatment Tool (JETT; North American Rescue, Greer, SC) (Figure 3). The unilateral $\mathrm{CRoC}$ device has been evaluated on humans, swine, manikin, and cadaver models. ${ }^{48-51}$ Assembly time to final application was reported to range between 55 and 90 seconds depending on the surface condition and casualty model used. ${ }^{50,51}$ In a swine model to control bleeding, just superior to the inguinal ligament, the device was $100 \%$ successful and took 4 to 9 turns of the device at this location. ${ }^{51}$ Both the JETT and SJT treat
A

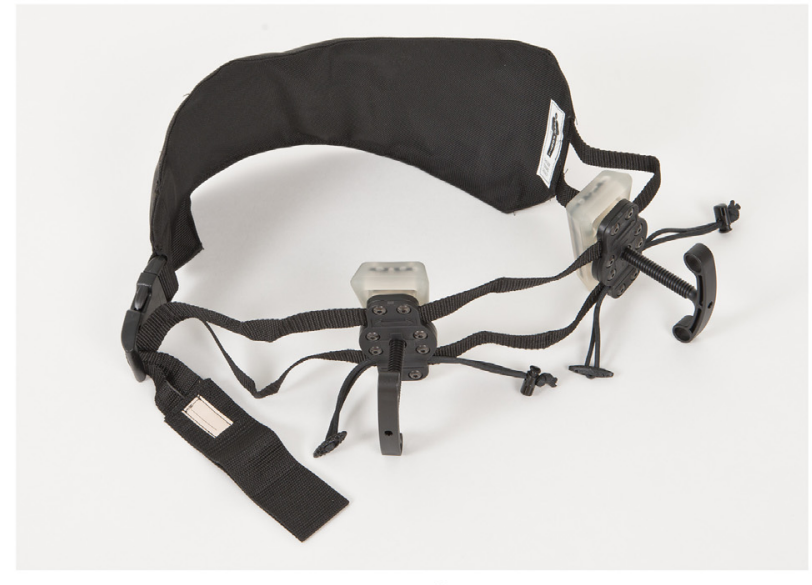

B

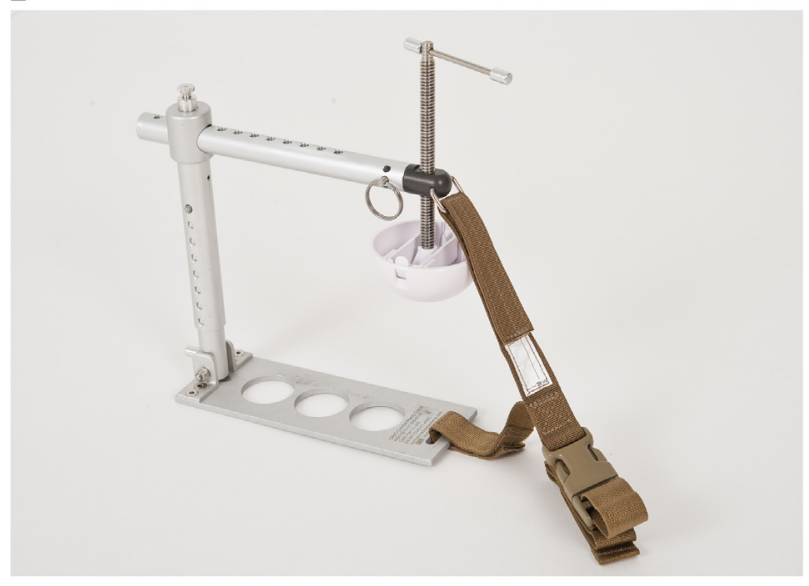

C

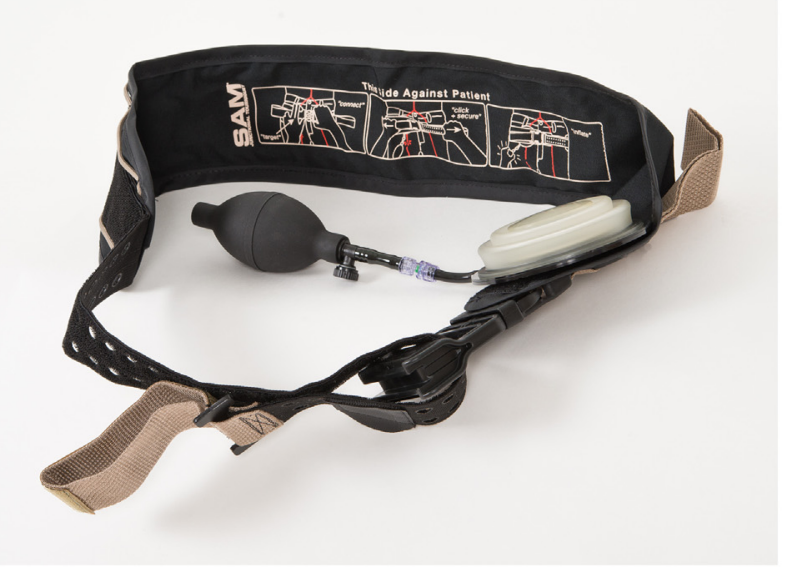

Figure 3. (A) Junctional Emergency Treatment Tool (JETT; North American Rescue, Greer, SC). (B) Combat Ready Clamp (CRoC; Combat Medical Systems, Fayetteville, NC). (C) The SAM Junctional Tourniquet (SJT; SAM Medical Products, Portland). 
Table 4. Tactical Combat Casualty Care recognized junctional tourniquets

\begin{tabular}{|c|c|c|c|c|c|c|}
\hline Product & Indications & $\begin{array}{c}\text { Application } \\
\text { time }^{a} \\
\end{array}$ & $\begin{array}{c}\text { Application } \\
\text { steps } \\
\end{array}$ & Weight & $\begin{array}{c}\text { FDA } \\
\text { Cleared }\end{array}$ & $\operatorname{Cost}^{a}$ \\
\hline $\begin{array}{l}\text { Sam Junctional Tourniquet } \\
\text { (SJT) and pelvic sling, Sam } \\
\text { Medical Products (www. } \\
\text { sammedical.com) }\end{array}$ & $\begin{array}{l}\text { Unilateral or bilateral } \\
\text { inguinal } \\
\text { hemorrhage; pelvic } \\
\text { fracture }\end{array}$ & $\begin{array}{l}25 \text { s per } \\
\text { manufacture }\end{array}$ & 4 steps & $1 \mathrm{lb}, 1 \mathrm{oz}$ & Yes & $\$ 450$ \\
\hline $\begin{array}{l}\text { Junctional Emergency } \\
\text { Treatment Tool (JETT), } \\
\text { North American Rescue } \\
\text { (www.narescue.com) }\end{array}$ & $\begin{array}{l}\text { Unilateral or bilateral } \\
\text { inguinal hemorrhage }\end{array}$ & $\begin{array}{l}60 \text { s per } \\
\text { manufacture } \\
\text { video }\end{array}$ & 5 steps & $1 \mathrm{lb}, 9.6 \mathrm{oz}$ & Yes & $\$ 360$ \\
\hline $\begin{array}{l}\text { Combat Ready Clamp (CRoC), } \\
\text { Combat Medical Systems } \\
\text { (www.combatmedical } \\
\text { systems.com) }\end{array}$ & $\begin{array}{l}\text { Unilateral inguinal } \\
\text { hemorrhage }\end{array}$ & $\begin{array}{l}59 \text { s per } \\
\text { research } \\
\text { study }^{b}\end{array}$ & 9 steps & $1 \mathrm{lb}, 6 \mathrm{oz}$ & Yes & $\$ 763$ \\
\hline
\end{tabular}

FDA, Food and Drug Administration.

${ }^{a}$ Approximate.

${ }^{b}$ From Mann-Salinas EA et al. ${ }^{51}$

combined pelvic and lower extremity injuries by incorporating a pelvic binder design with bilateral hemorrhage control devices at the femoral arteries just distal to the inguinal ligament (see Table 4). In a fresh human cadaver model designed to recreate arterial flow at normal physiologic blood pressures, blood flow was halted in the femoral arteries within 4 to 8 complete turns of the windlass handle, achieving success in controlling hemorrhage in all cases. Bilateral control of hemorrhage was achieved within 10 to 17 seconds after application, whereas the $\mathrm{CRoC}$ took 68 seconds to achieve bilateral control. ${ }^{52}$

Severe hemorrhage in the proximal inguinal region may be difficult to control with junctional devices. In this case, the compression of the abdominal aorta with an Abdominal Aortic and Junctional Tourniquet (AAJT; Compression Works, Birmingham, AL [Figure 4]) can be considered as a last resort to limit or eliminate blood flow at the distal abdominal aorta. The AAJT utilizes a wedge-shaped bladder that, inflated, pushes in on the lower abdomen and groin, compressing vasculature to stop arterial bleeding in junctional hemorrhage. Recently, the Food and Drug Administration approved it for application in the axilla region. A previous study reported that it takes between 80 and 140 pounds of external pressure over the distal abdominal aorta to stop blood flow, as assessed by ultrasonography. ${ }^{53}$

The abdominal aortic tourniquet is a pneumatic belt that can be applied in less than 60 seconds and delivers a constant pressure over the umbilicus for a prolonged period. It has been reported to be safe and effective for as long as 60 minutes of application. ${ }^{53}$ Similar to an extremity tourniquet, the tourniquet belt is applied around the patient and cinched down with a built-in windlass to add additional pressure. A pneumatic bladder is then inflated to a pressure that eliminates the femoral arterial pulse. This pressure ranged $150 \mathrm{~mm} \mathrm{Hg}$ to $230 \mathrm{~mm} \mathrm{Hg}$, with an average of $180 \mathrm{~mm} \mathrm{Hg}$, in 9 subjects when assessed by Doppler ultrasonography. ${ }^{54}$ A second study in human volunteers corroborated this finding and showed a 94\% effectiveness rate in eliminating blood flow in the common femoral artery. The one failure in this study was a person with above average height, weight, and body mass index. ${ }^{55}$ The AAJT has shown its effectiveness in 2 case reports from military operations in Afghanistan ${ }^{56}$ as well as in controlling upper extremity hemorrhage in a civilian trauma patient who had sustained a gun shot wound with a proximal brachial artery transection in the axilla. ${ }^{57}$

These newer junctional hemorrhage devices add bulk and weight that may limit their field use by the

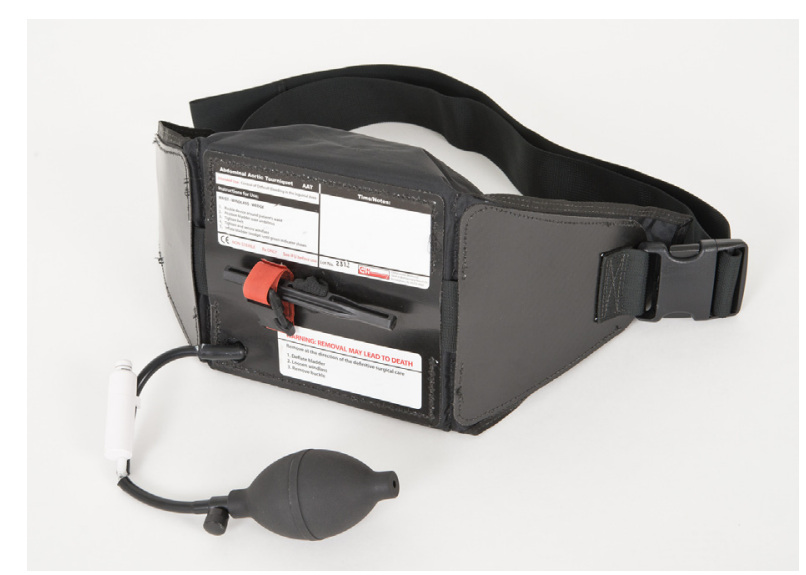

Figure 4. Abdominal Aortic and Junctional Tourniquet. 
individual wilderness medicine practitioner. Considerations may be made for expeditions where there are larger numbers of at-risk persons or if logistics are less of a concern, such as at base camps or where vehicles are being used.

\section{CASE RESOLUTION}

Before you and your friend left for your rock climbing trip, you packed a first aid kit with tourniquets and other appropriate supplies. Your quick application of the tourniquet to his leg stopped the bleeding and allowed a full assessment of the wound. You were well informed about the potential of a venous tourniquet and complications, monitoring of continued tourniquet use, and potential tourniquet conversion to a pressure dressing. Your initial attempt at tourniquet conversion resulted in brisk pulsatile bleeding. Luckily, the helicopter evacuation was completed within 2 hours, which allowed for your friend's femoral artery to be surgically repaired with near complete recovery.

\section{Conclusion}

Both the newcomer and experienced wilderness provider should be prepared to apply tourniquets in the appropriate situation. Device familiarity through training is the most important variable when deciding which of the 3 CoTCCC tourniquets to choose from. The application of tourniquets takes very little time and may have a profound impact on the outcome of the patient. When trauma occurs to junctional regions that are not amenable to the use of an extremity tourniquet, newer devices are available to prevent exsanguination.

\section{Acknowledgments}

The authors are in appreciation of the manufacturers and distributors for granting permission to use photos of their hemorrhage control devices as shown in Figures 2, 3, and 4 .

\section{References}

1. Bellamy RF. The causes of death in conventional land warfare-implications for combat casualty care research. Mil Med. 1984;149:55-62.

2. Champion HR, Bellamy RF, Roberts CP, et al. A profile of combat injury. J Trauma. 2003;54(Suppl):13-19.

3. Sauaia A, Moore FA, Moore EE, et al. Epidemiology of trauma deaths - a reassessment. J Trauma. 1995;38: 185-193.

4. Dorlac WC, Debakey ME, Holcomb JB, et al. Mortality from isolated civilian penetrating extremity injury. J Trauma. 2005;59:217-222.
5. Selby JB, Mathis JE, Berry CF, et al. Effects of isotonic saline solution resuscitation on blood coagulation in uncontrolled hemorrhage. Surgery. 1996;119:528-533.

6. Malone DL, Dunne J, Tracy JK, Putnam AT, Scalea TM, Napolitano LM. Blood transfusion, independent of shock severity, is associated with worse outcome in trauma. J Trauma. 2003;54:898-905.

7. Kauvar DS, Lefering R, Wade CE. Impact of hemorrhage on trauma outcome: an overview of epidemiology, clinical presentations, and therapeutic considerations. J Trauma. 2006;60(Suppl):3-11.

8. Bowers W, Hughes CW. Self-Help, First-Aid and Rescue. Surgical Philosophy in Mass Casualty Management. Springfield, MA: Charles C. Thomas; 1960.

9. Maughon JS. An inquiry into the nature of wounds resulting in killed in action in Vietnam. Mil Med. 1970; 135:8Y13.

10. Blackbourne LH, Baer DG, Eastridge BJ, et al. Military medical revolution: prehospital combat casualty care. J Trauma Acute Care Surg. 2012;73(Suppl 5):372-377.

11. Butler FK, Blackbourne LH. Battlefield trauma care then and now: a decade of Tactical Combat Casualty Care. J Trauma Acute Care Surg. 2012;73(Suppl 5): 395-402.

12. Butler FK. Tactical Combat Casualty Care: update 2009. J Trauma. 2010;69(Suppl):10-13.

13. Kragh JF, Walters TJ, Baer DG, et al. Practical use of emergency tourniquets to stop bleeding in major limb trauma. J Trauma. 2008;64(Suppl):38-50.

14. Kragh JF, Walters TJ, Baer DG, et al. Survival with emergency tourniquet use to stop bleeding in major limb trauma. Ann Surg. 2009;249:1-7.

15. Kragh JS, O'Neill ML, Walter TJ, et al. Minor morbidity with emergency tourniquet use to stop bleeding in severe limb trauma: research, history, and reconciling advocates and abolitionists. Mil Med. 2011;76:817-823.

16. Granville-Chapman J, Jacobs N, Midwinter MJ. Prehospital haemostatic dressings: a systematic review. Injury. 2011;42:447-459.

17. Smith AH, Liard C, Porter K, Bloch M. Hemostatic dressings in prehospital care. Emerg Med J. 2013;0:1-6.

18. Swan KG Jr, Wright DS, Barbagiovanni SS, Swan BC, Swan KG. Tourniquets revisited. J Trauma. 2009;66:672-675.

19. Markenson D, Ferguson JD, Chameides L, et al. Part 17: first aid. 2010 American Heart Association and American Red Cross guidelines for first aid. Circulation. 2010;122 (Suppl):934-936.

20. Blackbourne LH, Cancio L, Holcomb J, et al. First to Cut. Trauma Lessons Learned in the Combat Zone. Houston, TX: United States Army Institute of Surgical Research; 2009;15-17.

21. Butler FK, Giebner SD, McSwain N, Salomone J, Pons P, eds. Prehospital Trauma Life Support Manual. 7th ed. New York: Elsevier Publishing; 2010.

22. Brown M, Daya M, Worley J, et al. Experience with chitosan dressing in a civilian EMS system. J Emerg Med. 2009;37:1-7. 
23. Doyle GS, Taillac PP. Tourniquets: a review of current use with proposals for expanded prehospital use. Prehosp Emerg Care. 2008;12:241-256.

24. Lee C, Porter KM, Hodgetts TJ. Tourniquet use in the civilian prehospital setting. Emerg Med. 2007;24:584-587.

25. Butler F, Carmona R. Tactical Combat Casualty Care: from the battlefields of Afghanistan and Iraq to the streets of America. Tactical Edge. 2012;86-91.

26. Kragh JF, Swan KG, Smith DC, et al. Historical review of emergency tourniquet use to stop bleeding. Am J Surg. 2012;203:242-252.

27. Husum H, Gilbert M, Wisborg T, et al. Prehospital tourniquets: there should be no controversy. J Trauma. 2004;56:214-215.

28. Richey SL. Tourniquets for the control of traumatic hemorrhage: a review of the literature. World J Emerg Surg. 2007;2:28.

29. Dayan L, Zinman C, Stahl S, Norman D, et al. Complications associated with prolonged tourniquet application on the battlefield. Mil Med. 2008;173:63-66.

30. Beekly AC, Sebesta JA, Blackbourne LH, et al. Prehospital tourniquet use in Operation Iraqi Freedom: effect on hemorrhage control and outcomes. J Trauma. 2008;64 (Suppl):28-37.

31. Navein J, Coupland R, Dunn R. The tourniquet controversy. J Trauma. 2003;54(Suppl):219-220.

32. Kragh JF, Littrel ML, Jones JA, et al. Battle casualty survival with emergency tourniquet use to stop limb bleeding. J Emerg Med. 2011;41:590-597.

33. Eastridge BJ, Mabry RL, Seguin P, et al. Death on the battlefield (2001-2011): implications for the future of combat casualty care. J Trauma Acute Care Surg. 2012;73(Suppl):431-437.

34. Fitzgibbons PG, DiGiovanni C, Hares S, Akelman E. Safe tourniquet use: a review of the evidence. J Am Acad Orthop Surg. 2012;20:310-319.

35. Crenshaw AG, Hargens AR, Gershuni DH, Rydevik B. Wide tourniquet cuffs more effective at lower inflation pressures. Acta Orthop Scand. 1988;59:447-451.

36. Klenerman L. The Tourniquet Manual. London: Springer; 2003.

37. Walters TJ, Wenke JC, Kauvar DS, et al. Effectiveness of self-applied tourniquets in human volunteers. Prehosp Emerg Care. 2005;9:416-422.

38. Taylor DM, Vater GM, Parker PJ. An evaluation of two tourniquet systems for the control of prehospital lower limb hemorrhage. J Trauma. 2011;71:591-595.

39. Savage E, Pannell D, Payne E, et al. Re-evaluating the field tourniquet for the Canadian forces. Mil Med. 2013; 1178:669-675.

40. Kragh JF, O'Neill ML, Walters TJ, et al. The military emergency tourniquet program's lessons learned with devices and designs. Mil Med. 2011;176:1144-1152.

41. Kotwal RS, Montgomery HR, Kotwal BM, et al. Eliminating preventable death on the battlefield. Arch Surg. 2011;146:1350-1358.
42. Walters TJ, Mabry R1. Issues related to the use of tourniquets on the battlefield. Mil Med. 2005;170:770-775.

43. King DR, van der Wilden G, Kragh JF, Blackbourne LH. Forward assessment of 79 prehospital battlefield tourniquets used in the current war. J Spec Oper Med. 2012;12: 33-38.

44. Childers R, Tolentino JC, Leasiolagi J, et al. Tourniquets exposed to the Afghanistan combat environment have decreased efficacy and increased breakage compared to unexposed tourniquets. Mil Med. 2011;176: 1400-1403.

45. Weppner J, Lang M, Sunday R, et al. Efficacy of tourniquets exposed to the Afghanistan combat environment stored in individual first aid kits versus on the exterior of plate carriers. Mil Med. 2013;178:334-337.

46. Clumpner BR, Kragh JF, Westmoreland T, et al. Single versus double routing of the band in the combat application tourniquet. J Spec Oper Med. 2013;13:34-41.

47. Richey SL. Tourniquets for the control of traumatic hemorrhage: a review of the literature. World J Emerg Surg. 2007;2:1-10.

48. Kragh JF, Murphy C, Dubick M, et al. The tourniquet device concepts for battlefield hemorrhage control. Army Med Dept J. 2011 April-June:38-48.

49. Tovmassian RV, Kragh JF, Dubick MA, Baer DG, Blackbourne LH. Combat ready clamp medic technique. J Spec Oper Med. 2012;12:72-78.

50. Kheirabadi BS, Terrazas IB, Kragh JF, et al. In vivo assessment of Combat Ready Clamp (CRoC) to control junctional hemorrhage in swine. J Trauma Acute Care Surg. 2013;74:1260-1265.

51. Mann-Salinas EA, Kragh JF, Dubick MA, Baer DG, Blackbourne LH. Assessment of users to control simulated junctional hemorrhage with the combat ready clamp (CRoC). Int J Burns Trauma. 2013;3:49-54.

52. Gates KS, Baer L, Holcomb JB. Prehospital emergency care: evaluation of the junctional emergency tourniquet tool with a perfused cadaver model. J Spec Oper Med. 2014; 14:40-44.

53. Blaivas M, Shiver S, Lyon M, et al. Control of hemorrhage in critical femoral or inguinal penetrating wounds - an ultrasound evaluation. Prehosp Disaster Med. 2006;21:379-382.

54. Lyon M, Shiver SA, Greenfield EM, et al. Use of a novel abdominal aortic tourniquet to reduce or eliminate flow in the common femoral artery in human subjects. J Trauma Acute Care Surg. 2012;73(Suppl 1):103-105.

55. Taylor DM, Coleman M, Parker PJ. The evaluation of an abdominal aortic tourniquet for the control of pelvic and lower limb hemorrhage. Mil Med. 2013;178:1196-1201.

56. Anonymous. Case report: abdominal aortic tourniquet use in Afghanistan. J Spec Oper Med. 2013;2:1-2.

57. Croushorn J, McLester J, Thomas G, McCord SR. Abdominal aortic tourniquet controls junctional hemorrhage from a gunshot wound of the axilla. J Spec Oper Med. 2013;13:1-4. 